\title{
Grain Refinement Mechanism of Nickel-Based Superalloy by Severe Plastic Deformation - Mechanical Machining Case
}

\author{
Zhirong Liaoa, Mikhail Polyakovb, Oriol Gavalda Diaza, Dragos Axintea,*, Gaurav Mohantyb, Xavier \\ Maederb, Johann Michlerb, Mark Hardyc \\ a Rolls-Royce UTC in Manufacturing and On-Wing Technology, Faculty of Engineering, University of Nottingham, UK \\ ${ }^{b}$ EMPA, Swiss Federal Laboratories for Materials Science and Technology, Laboratory for Mechanics of Materials and \\ Nanostructures, Thun, Switzerland \\ ${ }^{c}$ Rolls-Royce plc, Derby, UK
}

\begin{abstract}
This paper studied the formation mechanism of white layer of a next generation nickel-based superalloy formed under severe plastic deformation induced by a mechanical material removal process. A graded microstructure of the white layer in the nickel-based superalloy has been revealed for the first time, which is composed of (i) a "dynamic recrystallisation" layer formed by nanocrystalline $(\sim 200 \mathrm{~nm})$ grains at the vicinity of the surface and (ii) a "dynamic recovery" layer with subgrain microstructures extending further into the subsurface. The mechanism of surface grain refinement was identified based on the results obtained via crystallographic and chemical analysis, as well as in-situ micro-mechanics experiments in the scanning electron microscope. It is found that in the top surface layer not only grain refinement but also the $\gamma$ ' phase dissolution occurs, changing drastically from the bulk material. Furthermore, it is shown how the high plastic strain and cutting temperature along the subsurface causes grain refinement in the white layer and grain elongation in the subsurface. The $\gamma^{\prime}$ precipitates in the recrystallisation layer are dissolved during the machining process, while the ultrahigh cooling rate suppresses the further precipitation of this phase, resulting in the supersaturation of $\gamma$ grains or minimized $\gamma^{\prime}$ precipitates in the top surface layer. Hence, the grain refinement does not result in an increase of mechanical stiffness but a deterioration of mechanical properties due to the dissolution of the strengthening phase $\gamma$, which leads to a lower strength and increased ductility. Machining is generally treated as a cold-working process. However, according to our findings hotworking with dynamic recrystallisation and recovery, as well as phase evolution, occurs in the white layer of nickel-based superalloys.
\end{abstract}

Key words: White layer; Superalloys; Grain refinement; Severe plastic deformation; Machining and surface integrity 


\section{Introduction}

Nickel-based superalloys consist of $\mathrm{L}_{2}$ crystal structured gamma prime $\left(\gamma^{\prime}\right)$ phase precipitation in the disordered face centred cubic (FCC) gamma $(\gamma)$ matrix to strengthen the material at high temperatures. Consequently, these materials are widely used for the manufacture of safety critical components for high-value industries (e.g. aerospace, marine, nuclear) [1,2]. Mechanical machining is the main material removal process currently used to achieve the final component geometry at the surface roughness required for these critical applications [3]. However, due to the mechanical engagement between the cutting tool and workpiece, severe plastic deformation (SPD) always occurs in the workpiece superficial layer, leading to surface alterations which are the main causes of local modifications of material properties [4]. Of these superficial layer modifications, the formation of a white layer, also known as a 'non-etching' layer, is an artefact that appears featureless and white when viewed under an optical microscope after polishing and etching. While the fatigue life is of key importance when nickel-based superalloys are used in safety critical conditions, white layers are generally considered to be detrimental to fatigue life and stress corrosion cracking [5].

It has been found that grain refinement occurs within the machining induced white layer which presents a nanocrystalline microstructure $[6,7,8,9]$. This ultrafine grain structure is believed to be primarily attributed to recrystallisation (RX) induced by the severe plastic deformation of the machining process (e.g. at high strain rates of $10-10^{5} / \mathrm{s}$ and strains of $1-15$ ) $[10,11,12]$. More interestingly, while this nanocrystalline superficial layer of nickel-based superalloys induced by machining is undesired for safety critical aero-engine applications, researchers have also reported that the ultrafine grained microstructures, with an extremely large fraction of grain boundaries, are favourable to be employed to improve material performance, i.e. higher hardness, strength, wearresistance and fatigue life, in other materials (e.g. titanium, copper and aluminium) $[13,14,15]$. This grain refinement has drawn tremendous interest from scientists and various methodologies of severe plastic deformation such as laser shock peening [16,17,18], cold rolling [19], equal channel angular 
pressing (ECAP) [20, 21], high pressure torsion (HPT) [22,23] as well as mechanical machining [24] have been developed to achieve the refined grains. Although machining has been shown to be an effective way to achieve SPD for different materials, such as copper [10], aluminium [25] and titanium $[26,27]$ for improving their mechanical properties, the machining induced white layer grain refinement of nickel-based superalloys is proven to significantly reduce their fatigue life (e.g. 40 times reduction in low cycle fatigue test) $[28,29]$ and therefore, this needs further investigations.

One of the challenges in characterising the nanocrystalline superficial layer formed during machining is that bulk tests cannot be performed due to the small thickness of the white layer (a few microns) and consequently, micromechanics need to be employed. Furthermore, the machining of nickel-based superalloys results in a unique combination of large values of strain and temperature. These two conditions together are not found in other SPD processes due to the lower process temperature used. In addition, when machining other materials the temperatures reached during cutting are relatively low (e.g. in copper only approx. 0.4 melting temperature) [10]. Therefore, this unique combination of high strains and strain rates at high temperatures is exclusive to materials such as nickel-based superalloys where high values of strength are maintained at high temperatures together with low thermal conductivity [30]. Previous research through X-ray diffraction (XRD) also suggested that all major phases contained in the bulk material were present in the white layer and there was no clear phase transformation in this thin layer of machined nickel-based superalloys [31]. However, considering its detrimental effects to their fatigue performance as well as the difficulty in characterising this thin layer, the authors would question this conclusion. Specifically, the coherently precipitated face centred cubic lattice $\gamma^{\prime}$ phase has similar lattice parameters compared to the $\gamma$ matrix, making the phase identification process very challenging. In addition, the thin thickness of the white layer may also lead to the failure of employing XRD due to the penetration of X-rays into bulk material. Thus, the fact that the fatigue performance is deteriorated due to the white layer, together with the lack of research focusing on the microplasticity understanding of the recrystallisation effects, draw the need 
of systematic investigation of the micro-mechanism of white layer. Consequently, one would question: why does this refined grain layer in nickel-based superalloys not provide a surface enhancement but deteriorate the material performance instead?

To this end, the microstructure evolution mechanism in the superficial layer of machined nickelbased superalloy is of great practical importance because of the close relationship between the microstructure (e.g. grain structure and $\gamma^{\prime} / \gamma$ distribution) and material performance of these specific alloys. While the governing mechanisms of the machining induced white layer in other materials, such as copper [10], titanium [26, 27] or alloyed steels [32, 33], have been revealed recently, its formation mechanisms in nickel-based superalloys and the resultant microstructural changes is still pending. Moreover, as the microstructure of nickel-based superalloys is unique when compared to pure metals or alloy steels, due to the high volume fraction of coherent $\mathrm{L} 1_{2}$ crystal structure $\gamma^{\prime}$ precipitates in a disordered $\gamma$ matrix which results in low thermal conductivity and high strength even at high temperatures, it could be imagined that the white layer formation mechanism of this alloy would remain unique from other materials. Thus, the formation mechanism of the machining-induced white layer in nickel-based superalloys is worth investigating in order to further explain its detrimental impact in the mechanical performance of the material. In this study, a high-strength polycrystalline nickel-based superalloy, S135H [34], was chosen to study the mechanism of grain refinement layer generation due to aggressive machining. A thin white layer $(3 \sim 4 \mu \mathrm{m})$ of refined grain size $(\sim 200 \mathrm{~nm})$, which is significantly smaller than that in bulk material $(\sim 5 \mu \mathrm{m})$, was achieved in the superficial layer of the machined surface. The underlying formation mechanism of this thin severe plastic deformation layer induced by machining was revealed with detailed high resolution analysis and microplasticity investigations. 


\section{Experimental procedures}

\subsection{Material and processing parameters}

The material used in this research is a new nickel-based superalloy $(\mathrm{S} 135 \mathrm{H})$ that has been designed to have a $\gamma^{\prime}$ content of 54\% for potential aero-engine applications [34]. The chemical composition of this alloy is presented in Table 1. The alloy was manufactured by powder metallurgy via hot isostatic pressing, followed by a solution treatment at $1190^{\circ} \mathrm{C}$ for 2 hours with air cool and aged with $850^{\circ} \mathrm{C}$ for 4 hours to reach a fine grained microstructure $(\sim 5 \mu \mathrm{m}$ average dia.).

Table 1 Chemical composition of S135H (wt \%)

\begin{tabular}{lllllllllllllll}
\hline Ni & Cr & Co & Nb & Ta & Al & Ti & W & Fe & Mn & Mo & C & B & Zr \\
\hline Bal & 12.3 & 4.0 & 2.1 & 4.6 & 3.8 & 2.6 & 3.2 & 3.4 & 0.5 & 0.6 & 0.02 & 0.02 & 0.06 \\
\hline
\end{tabular}

An orthogonal cutting process, i.e. dry plunge turning, has been carried out with a solid carbide parting tool $\left(0^{\circ}\right.$ rake angle, $7^{\circ}$ clearance angle and a $10 \mu \mathrm{m}$ edge radius $)$ under an aggressive cutting condition with high cutting/feed speed and tool wear (cutting speed V=80 $/ \mathrm{min}$, feed speed $\mathrm{f}=0.1 \mathrm{~mm} / \mathrm{rev}$, average flank wear $\mathrm{VB}=0.3 \mathrm{~mm}$ ) to generate a severely plastic deformed layer (white layer) on the machined surface. The surface roughness before machining is $0.58 \mu \mathrm{m}$ while after machining is $1.29 \mu \mathrm{m}$.

\subsection{Specimen characterisation}

The cross-sections of the machined sample were finely polished and etched with $10 \%$ orthophosphoric acid in distilled water while exposed to a voltage of $10 \mathrm{~V}$ for 7-10s to reveal, under the FEG-SEM (JEOL 7100), the white layer and the $\gamma^{\prime}$ microstructure in the bulk material. An electron probe microanalysis (EPMA, JEOL JXA-8200) was also employed for the elemental mapping of this thin layer. To study the grain structure, the non-etched sample was first analysed via ion channelling contrast (ICC) imaging at $30 \mathrm{kV}$ and $15 \mathrm{pA}$, using a focused ion beam scanning electron microscope 
(FIB-SEM, Tescan Lyra FEG). A lamella of about $100 \mathrm{~nm}$ thick was then lifted-out from the machined superficial layer for grain orientation mapping by Transmission Kikuchi Diffraction (TKD). SEM conditions of $30 \mathrm{kV}$ and $5 \mathrm{nA}$ were used for the mapping with $15 \mathrm{~nm}$ step size, using a DigiView V EBSD camera from EDAX, The data have been analysed with the OIM v7 software. The lamella has also been imaged via transmission electron microscopy (TEM) with a FEI Titan Themis system equipped with a SuperEDX system (FEI) for both energy dispersive X-ray (EDX) mapping and microstructure evaluation. The DF-STEM images were collected in an ADF (Annular Dark-Field) imaging configuration, with a combination of mass-thickness contrast and orientation contrast evident. Thus, both the grain orientation mapping and high resolution chemical/microstructural information could be obtained from the same area in order to compare the phase transition with the grain evolution in the thin white layer.

\subsection{Micro-mechanics characterisation}

To study how the elastoplastic material mechanical properties change within the thin white layer (approx. 3-4 $\mu \mathrm{m}$ ) induced by the severe plastic deformation during the machining process, uniaxial cyclic loading-unloading compression tests of micro-pillars were performed on both the white layer and the bulk material. The micro-pillars were prepared near the machined surface $(1.5 \mu \mathrm{m}$ from micropillar centre to surface) and in the bulk material with an approximate diameter of $3 \mu \mathrm{m}$ and a height of $7 \mu \mathrm{m}$, by using a Tescan Lyra dual FIB/SEM (FEG). For each sample at least 3 pillars were tested. The loading-unloading tests were conducted with an Alemnis Nanoindenter equipped with a diamond flat punch at displacement intervals of 0.02 and $0.1 \mu \mathrm{m}$ and a constant strain rate of $0.1 \mathrm{~s}^{-1}$ at room temperature. 


\section{Results}

\subsection{Grain morphology of the white layer}

In order to understand the microstructure of the white layer, the bulk material was first studied, revealing a trimodal size distribution of $\gamma^{\prime}$ precipitates, as shown in the SEM and EDX images in Fig. 1. The size of primary, secondary and tertiary $\gamma^{\prime}$ precipitates was found to be around $3 \mu \mathrm{m}, 400 \mathrm{~nm}$ and $20 \mathrm{~nm}$, respectively. The EDX maps show that the main constitutive elements of $\gamma^{\prime}$ precipitates are Al and $\mathrm{Ti}$, while $\mathrm{Cr}$ is mainly located in the $\gamma$ matrix. These $\gamma^{\prime}$ precipitates are the main contributors to the enhanced strength of the $\mathrm{S} 135 \mathrm{H}$.
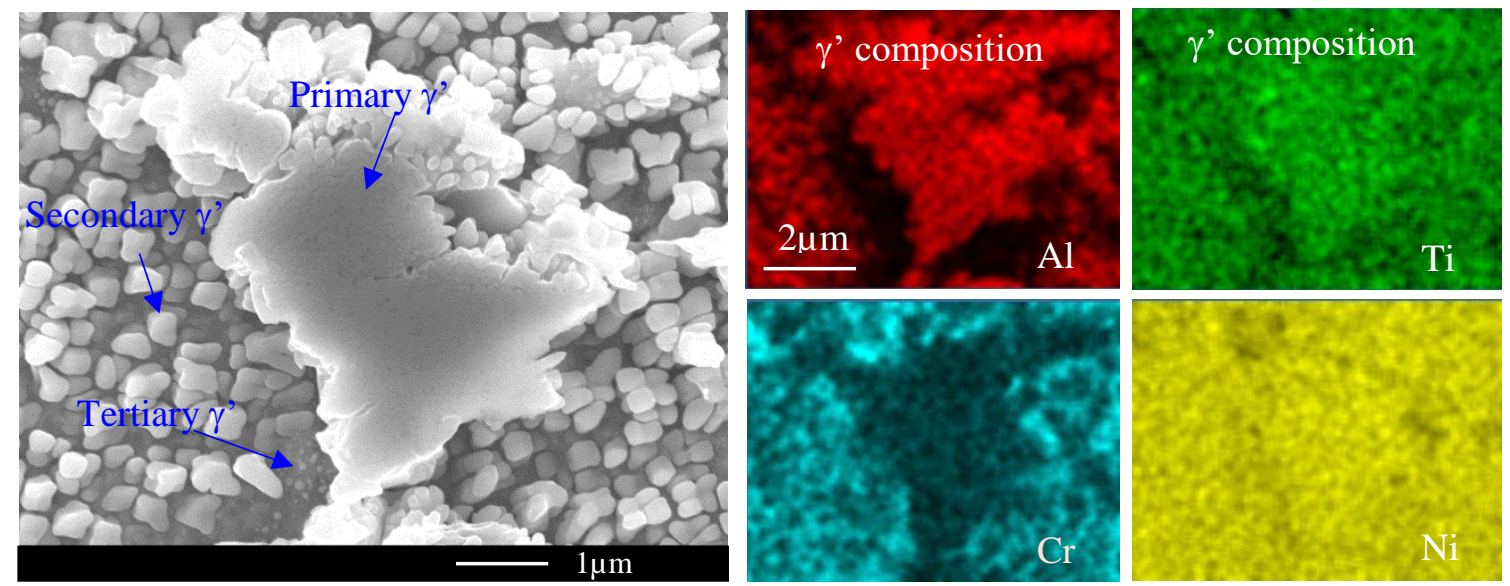

Fig. 1 Secondary Electron micrograph of an etched S135H microstructure revealing a trimodal size distribution of $\gamma^{\prime}$ phase and corresponding EDX maps

A polished and etched cross-sectional image of the superficial layer after machining showing how the thickness of the white layer varies between 3-4 $\mu \mathrm{m}$ can be observed in Fig. 2 at two different magnifications. Adjacent to the white layer there is a clear area (around $12 \mu \mathrm{m}$ thickness) showing a high extent of material deformation affected by the mechanical effect of the cutting process. It is evident that during machining, the engagement of the cutting tool with the workpiece causes microstructural changes within the surface layer, and these influences decrease from the free surface toward bulk material. However, from the SEM observation, it is still not evident how this surface layer 
is affected. Consequently, electron transparent samples containing information of the surface and subsurface from the non-etched sample have been lifted out (as shown in red box in Fig. 2) for indepth characterisation of the microstructure via TEM and TKD.
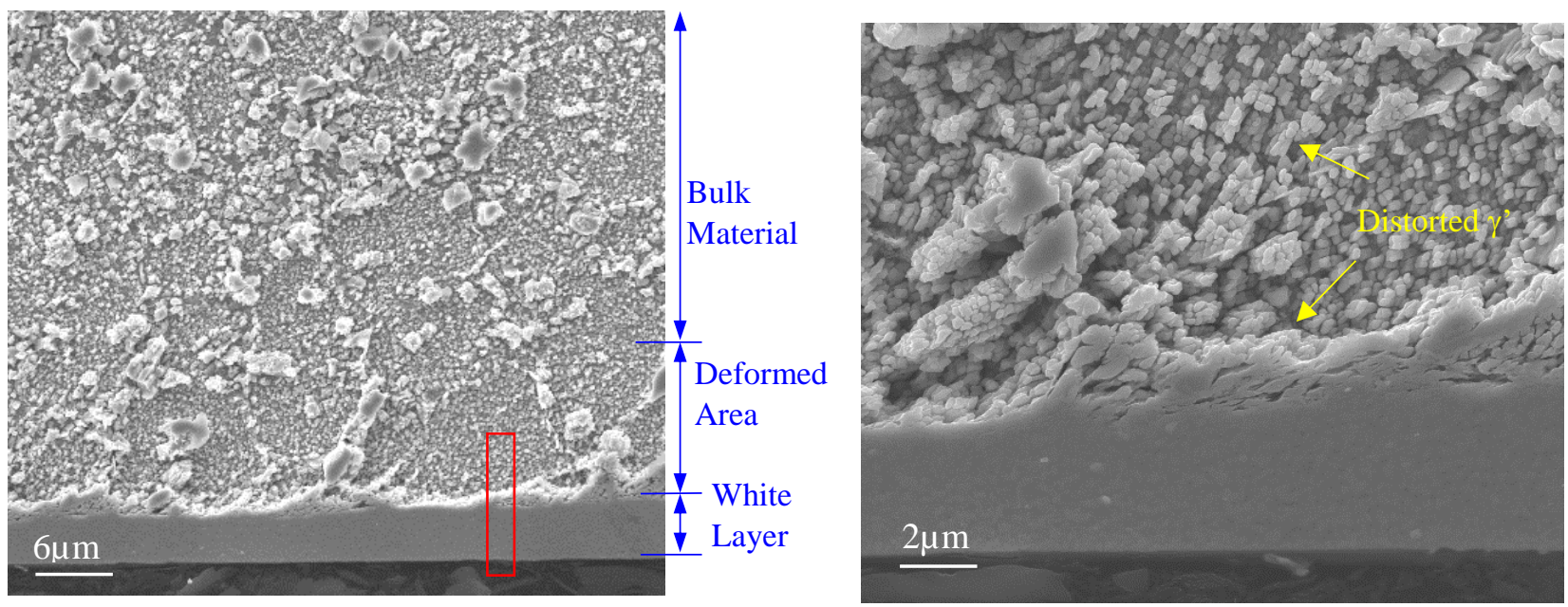

Fig. 2 Secondary Electron micrograph of etched sample after machining revealing subsurface changes in the white layer and material distortion in the bulk material. The red rectangle shows the location of the TEM lamella, also used for TKD.

As observed in Fig. 2, the white layer is insensitive to etching and featureless, thus two hypotheses for the formation mechanism of this layer could be proposed: i). only a recrystallisation process occurred, leading to small grain size which could affect the etching and there is no phase change in this layer; ii). both the grain size and $\gamma^{\prime}$ precipitates have been changed during mechanical cutting. To evaluate these two hypotheses the main forming elements of $\gamma^{\prime}$ (Al, Ti and Ta) and $\gamma(\mathrm{Cr})$ were analysed by electron probe microanalysis mapping the superficial layer. Fig. 3 shows that in the white layer, the elements are dramatically dispersed and featureless compared to the bulk material where the $\gamma^{\prime} / \gamma$ phase can be easily distinguished. Consequently, it could be commented that a phase transition might be happening within the white layer. This is contrary with previous research studying the white layer formation in nickel-based superalloy, which suggested that no dissolution and precipitation occurs $[6,31]$. 

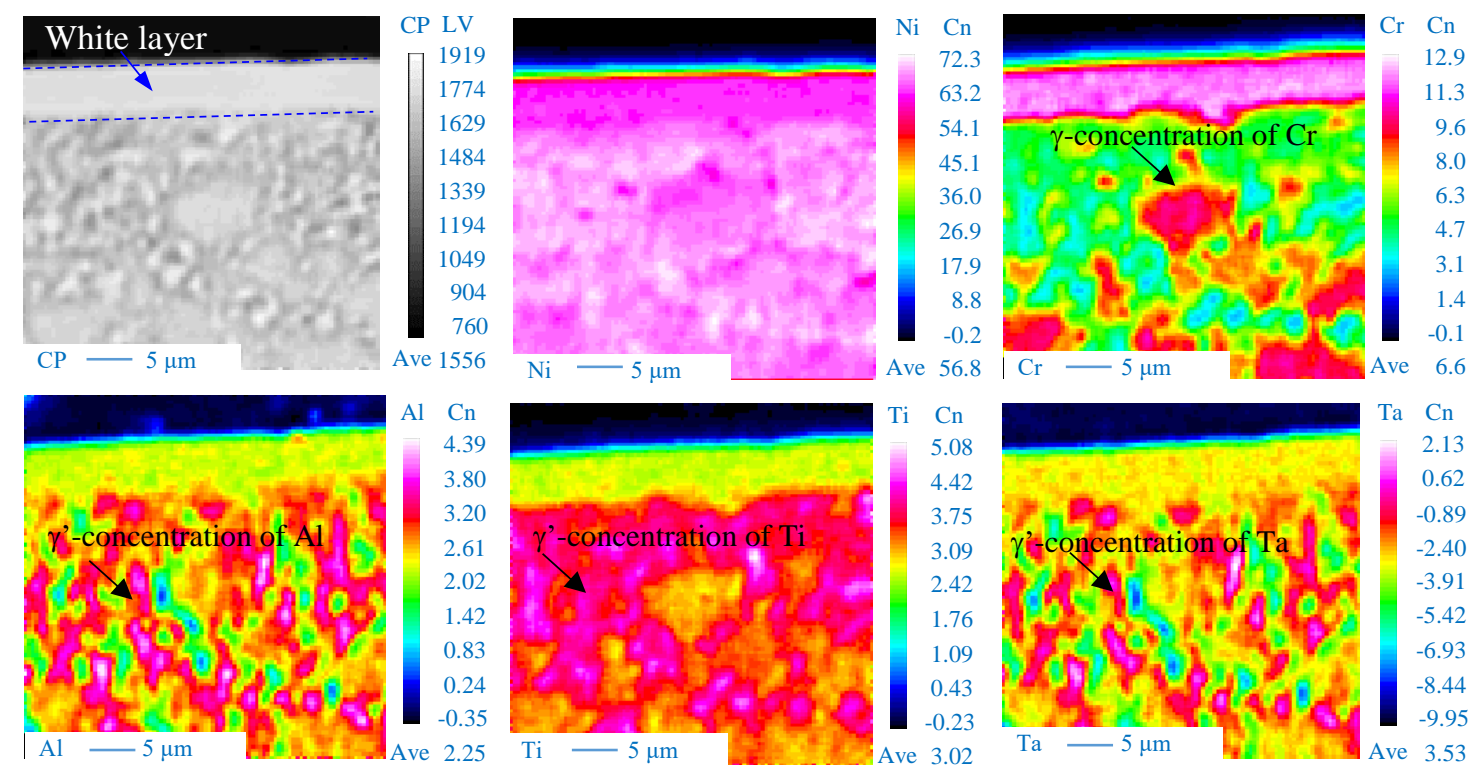

Fig. 3 Electron probe microanalysis mapping across the superficial layer of a machined surface showing a featureless distribution of elements in the white layer.

To further understand the recrystalisation mechanism in the white layer, ion channelling contrast (ICC) imaging was conducted in the superficial layer (Fig. 4), whereby both the crystallographic orientation and $\gamma^{\prime} / \gamma$ contrast could be revealed. The ICC imaging shows the ultrafine grain size formed in the white layer, indicating that grain refinement occurs in this superficial layer. Severely deformed grain morphology has also been captured adjacent the grain refinement layer, where the grain size is dramatically increased to around $7 \mu \mathrm{m}$. Surprisingly, this change in the grain size from ultrafine (hundreds of $\mathrm{nm}$ ) to several microns is abrupt, which differs from other severe plastic deformation processes (e.g. laser shock peeing) where a gradual transition of the grain size was reported [18]. In ICC, it is also interesting to see that the different contrast between the $\gamma / \gamma^{\prime}$ phase microstructure was revealed due to the different ion etching rate of $\gamma$ and $\gamma^{\prime}$ phases. However, this $\gamma / \gamma^{\prime}$ contrast was only observed in the substrate layer where large grains are present, while it could not be appreciated in the recrystallisation layer due to its featureless nature. 


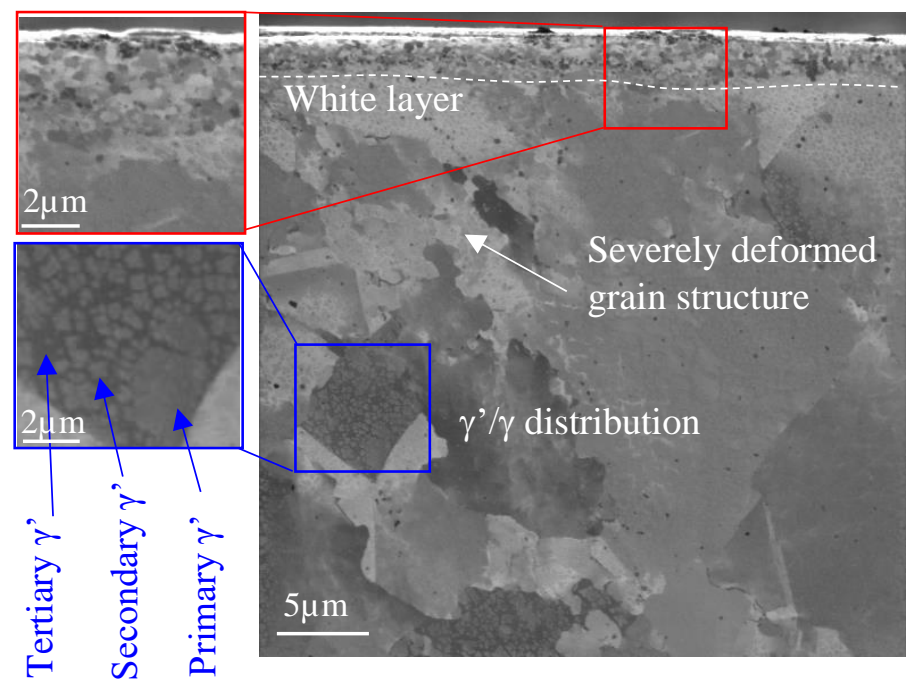

Fig. 4 Ion contrast channelling imaging of the subsurface on machined sample revealing the grain refinement in white layer as well as $\gamma / \gamma^{\prime}$ contrast microstructure in bulk area.

The grain structure in the white layer is too small to be revealed by conventional EBSD, therefore TKD has been made on a lift-out thin lamella (location in Fig. 2), which provides a significant higher spatial resolution and quality results compared with the EBSD. As shown in Fig. 5, it reveals a recrystallisation layer (of around $2 \mu \mathrm{m}$ thickness) with an approximatively grain size of $200 \mathrm{~nm}$ in the superficial layer showing blocky grain structure with only a low amount of small angle boundaries. Interestingly, below the recrystallisation layer, a transition layer (of around $1.5 \mu \mathrm{m}$ thickness) is formed with low angle grain boundaries and subgrains, while larger grain in the bulk material, with a lot of small angle grain boundaries and misorientation gradient due to the plastic deformation is found in the subsequent bulk material layer due to the dominating high plastic deformation. Thus, based on the differences in grain structures, the superficial layer can be divided into recrystallisation layer, transition layer and deformed bulk layer (as shown in Fig. 5). It can also be seen that in the recrystallisation layer, although the grain size is more than 10 times smaller than the bulk material, the grains have nucleated and grown properly into individual crystals with lower intragranular misorentation and defects. In the transition layer both the new grains with low grain boundaries and subgrains were found due to the reduction of thermal and strain energy from the top machined surface towards the substrate. In the 
subsequent bulk layer (further from the cutting region), large grains with high intragranular misorientations are found as there is a lack of enough energy (thermal and mechanical) to nucleate new grains. Corroborating this with the previous observations (Fig. 2-4) it could be concluded that the difficult-to-etch white layer is not a simple recrystallisation layer but it also consists of a layer of subgrains. This imaging gives a more detailed description of the white layer formation in a machining process, as the previous research with EBSD work [4] was not able to achieve the spatial resolution necessary for such a highly deformed and ultrafine grain structure.

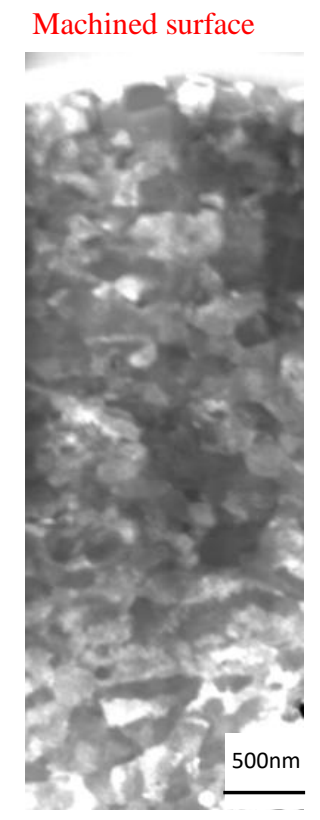

(a)

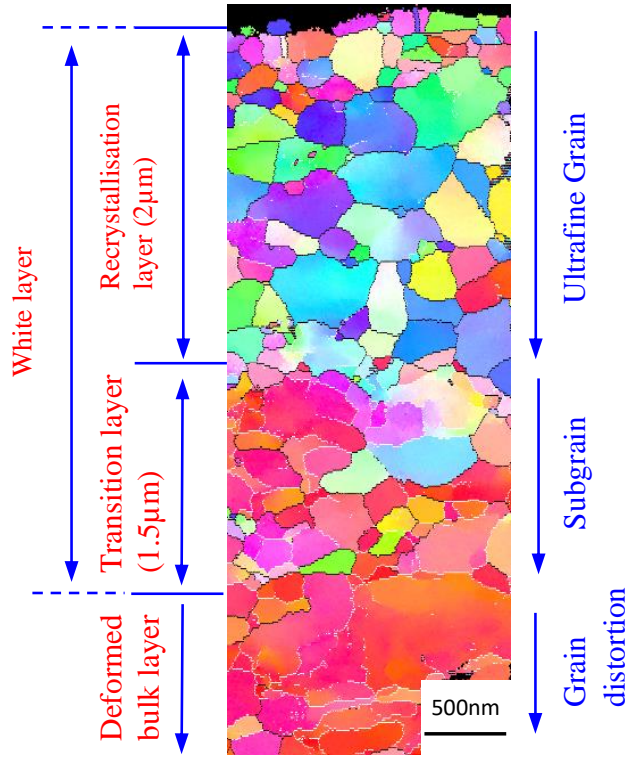

\section{(b)}

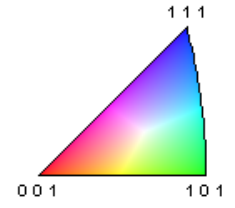

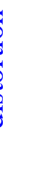

Fig. 5 STEM (a) and SEM-TKD (b) images of the superficial layer of a machined workpiece revealing that the white layer can be divided into two layers: recrystallisation layer and transition layer

\subsection{Plastic behaviour and microstructure of white layer}

It has been reported that grain refinement under severe plastic deformation improves the material mechanical performance, known as the "Hall-Petch strengthening" [35]. However, its applicability in refined structures of nickel-based superalloys emerging from a machining process is not clear. Up to now, only micro-hardness investigations have been reported in this machined superficial layer, while other micromechanical properties such as fatigue strength, dimensional stability and relaxation 
phenomena have rarely been studied, due to the small thickness of this layer. Since the mechanisms of plastic deformation and dislocation accumulation presumably control the fatigue behaviour of the material, in order to investigate the material deterioration of this thin layer, a loading-unloading compression test of micropillars on both the bulk material and white layer has been conducted. This microplasticity test can allow an understanding of how these two materials (i.e. bulk material and white layer) behave in an elastoplastic regime.
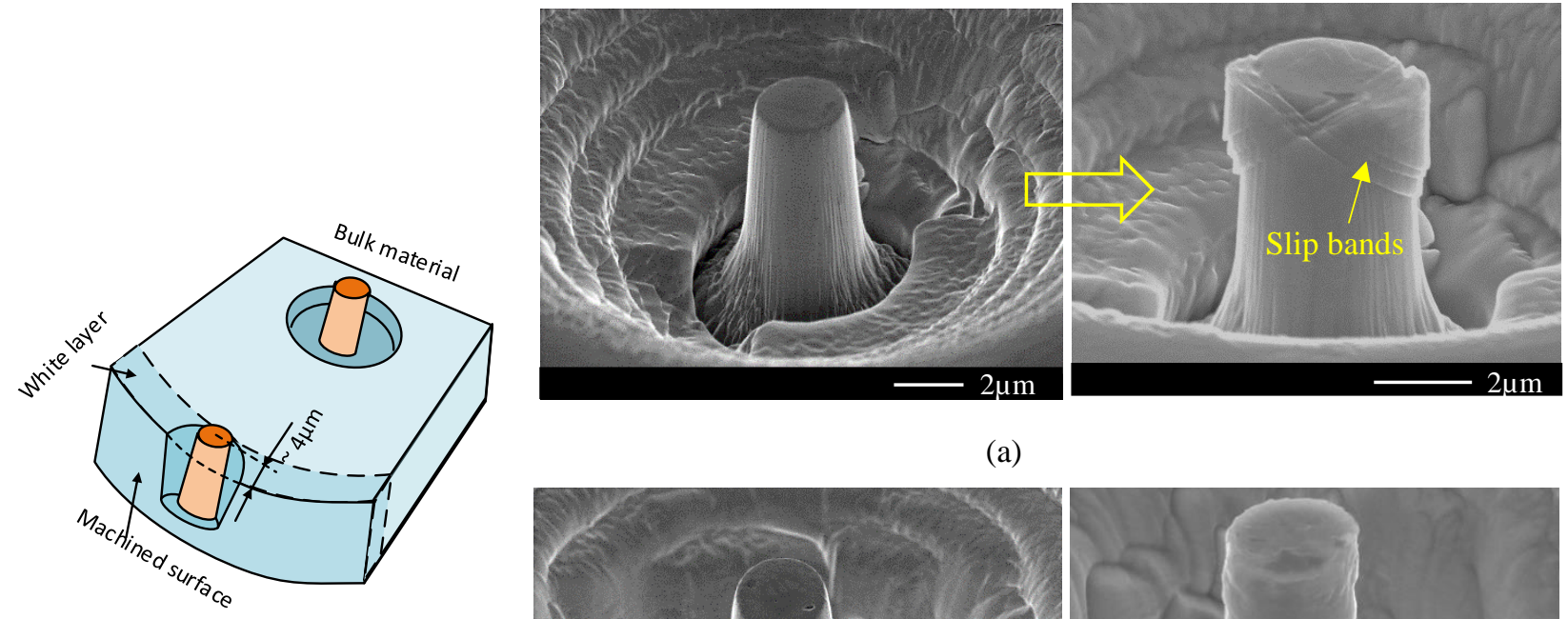

(a)

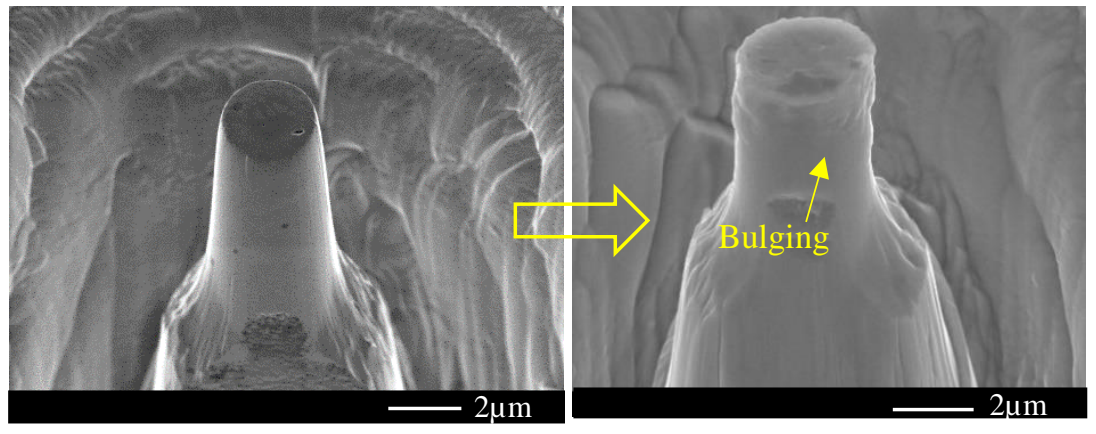

(b)

Fig. 6 Micropillars for cyclic compression test on the (a) bulk material and (b) white layer (see schematic for locations of the pillars)

Fig. 6 shows that the material deformation mechanisms of the white layer and the bulk material are completely different: in the bulk material the pillar shows the displacement of slip planes during the compression loading-unloading while in the white layer only bulging of the pillar occurs. More interestingly, from the stress-strain curve (Fig. 7a), it can be observed that in the bulk material the yield point is well defined (around $1000 \mathrm{MPa}$ ) while when the applied stress exceeds, this yield point microplastic deformation starts to dominate the process, i.e. plastic strain occurs. In contrast, the white 
layer seems to plastic deform without having any clear yield point (Fig. 7b). More clearly, it can be observed in Fig 7c and Fig.7d how the plastic strain and plastic strain energy (energy dissipated in plastic deformation) for the bulk material start to increase after the stress reaches a critical value (i.e. yield stress-1000 MPa), while in white layer there is almost no elastic recovery even at low stresses (e.g. 300MPa). This significant plasticity explains the deterioration of the material mechanical performance.

In monocrystalline metals the micro-elasticity is associated with reversible dislocation motion, while micro-plasticity is related with the break-away from strong pinning points, subsequent motion and interaction of the dislocations [36]. The observed high plasticity phenomenon, on one hand, can be speculated as the Bauschinger behaviour of the white layer, which is due to the tensile plastic strains induced by the thermal effect with high dislocation density $[4,7]$ and when compressive strain is applied the Bauschinger effect changes the unloading yield stress. On the other hand, since the $\gamma^{\prime}$ precipitation contributes to the prevention of the penetration of dislocations from the $\gamma$ constituent, it can also be assumed that the loss of the $\gamma^{\prime}$ phase in white layer could contribute to the dominating plastic behaviour and the low value of yield strength. This will also be investigated in later study of the phase transition of the white layer.

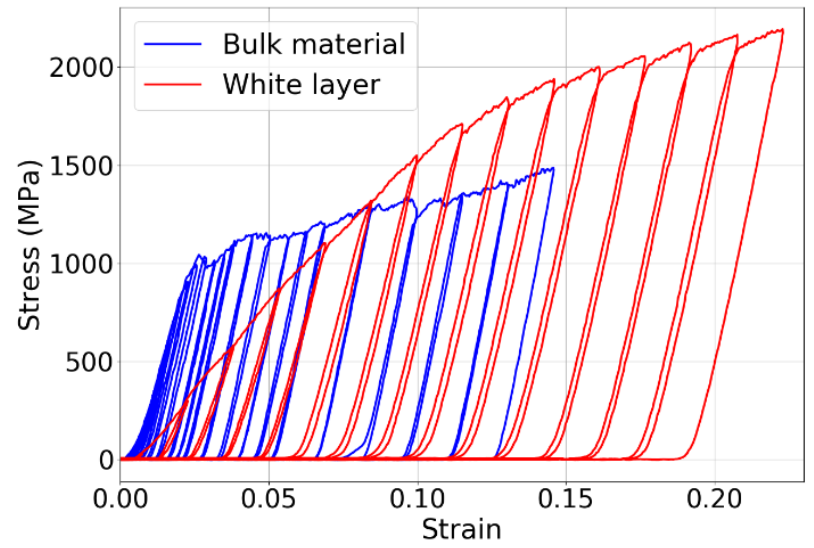

(a)

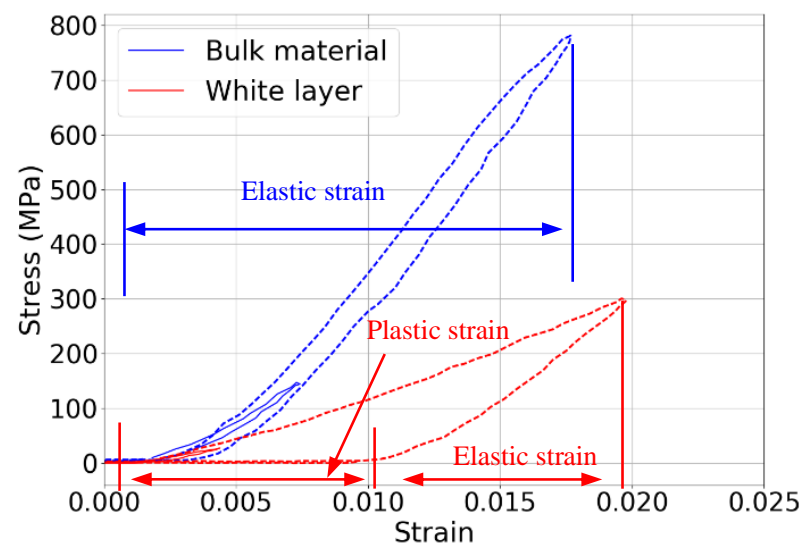

(b) 


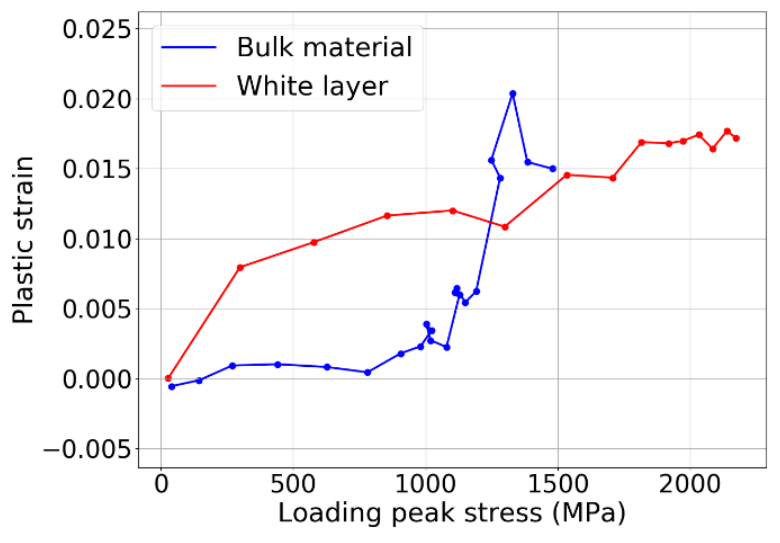

(c)

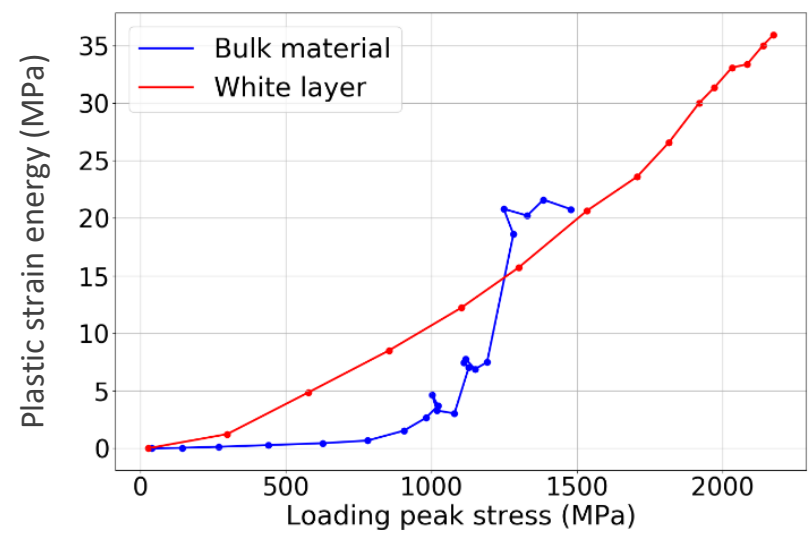

(d)

Fig. 7 Cyclic compression test of micro-pillars in the white layer and bulk material: (a) and (b) stress-strain curves of displacement controlled loading-unloading compression tests, (c) plastic strain and (d) plastic strain energy (plastic area under the stress-strain curve) vs loading stress

The TEM image of the bulk material (Fig. 8a) shows the clear contrast of cuboidal $\gamma^{\prime}$ precipitates along the $\gamma$ channels. A long grain boundary can be also observed, indicating the grain size in the bulk material. In the white layer (Fig. 8b), no $\gamma / \gamma^{\prime}$ contrast has been observed, which indicates that the $\gamma^{\prime}$ has been dissolved or refined during the machining process. However, the microstructure of the white layer is clear, including grain boundaries, twin boundaries (similar to the twinning observed in [16] and [18]), and the dislocation defects.

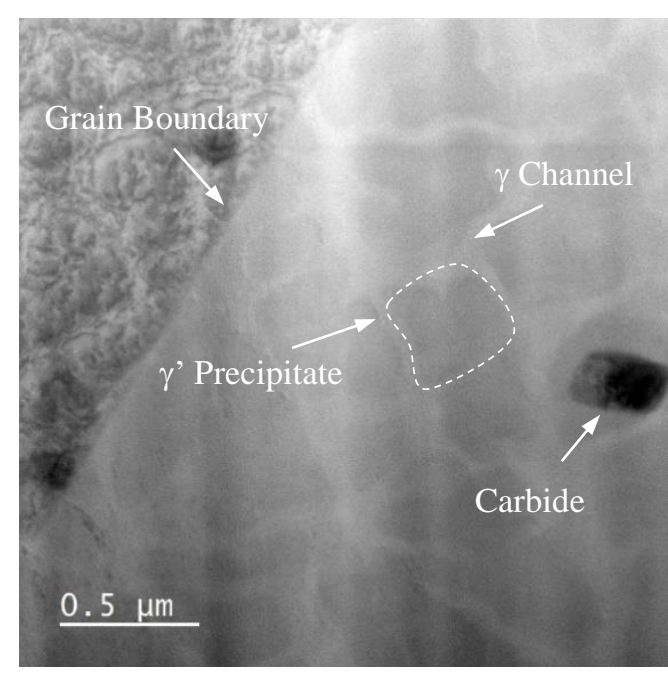

(a)

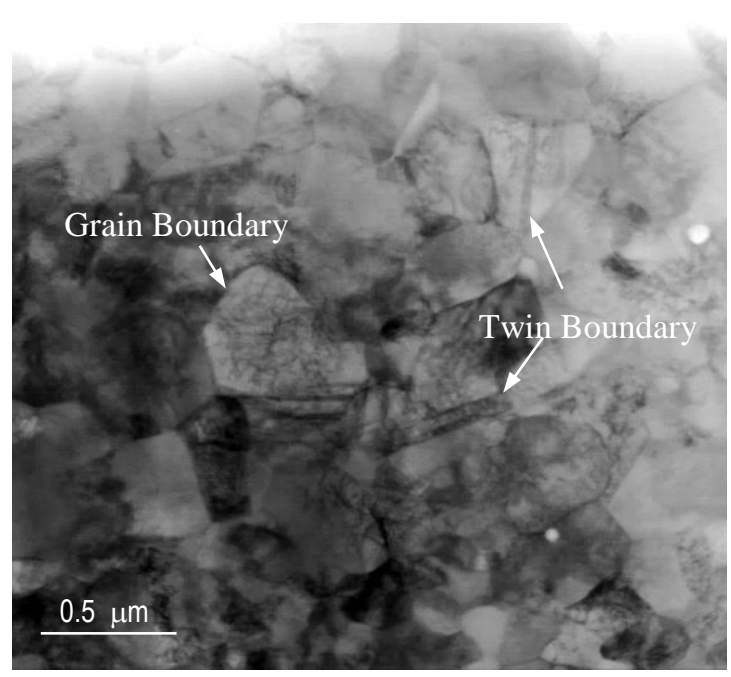

(b) 
Fig. 8 TEM micrographs of (a) bulk material showing big grains and $\gamma^{\prime} / \gamma$ contrast and (b) white layer showing nanocrystalline.

The grain boundary map obtained from TKD analysis (Fig. 9) shows that the twin boundaries are mainly concentrated in the recrystallisation layer, presumably due to the high plastic strain and temperature induced by the machining process. The low angle grain boundaries (LAGB, $<20^{\circ}$ ) are mainly concentrated in the transition area and deformed bulk layer. These LAGBs store the dislocation energy necessary to generate the nuclei for recrystallisation crystals, but the recrystallisation could not occur in these two areas due to the reduced temperature and strain with the increased distance from the tool-workpiece interaction area, i.e. free surface. These low-angle grain boundaries are mainly generated from the high plastic strain induced dislocation activities. In the recrystallisation layer, the amount of LAGB is reduced and the formation of high angle grain boundaries (HAGB) is observed.
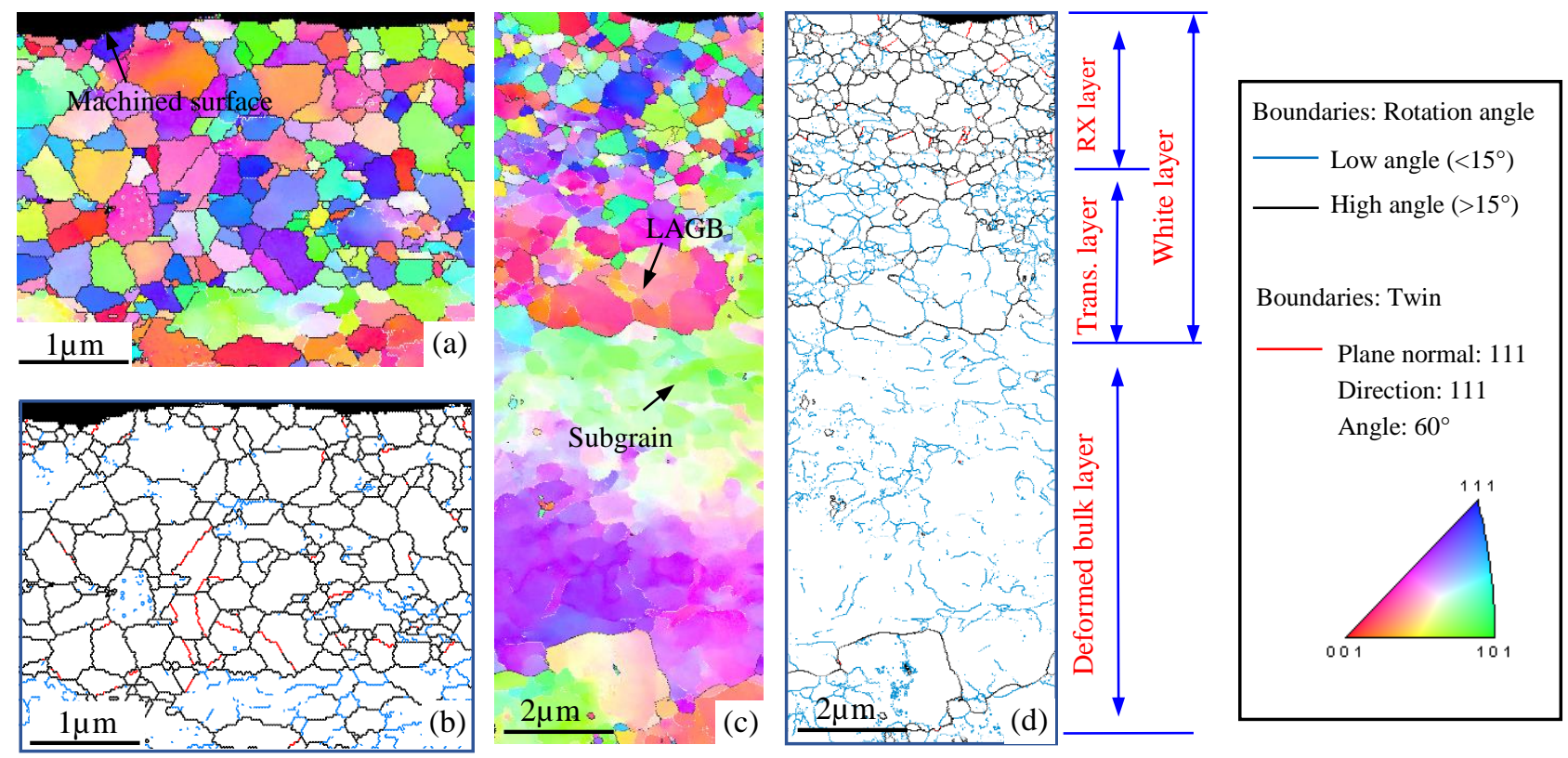

Fig. 9 Grain information of Transmission Kikuchi Diffraction in the superficial layer at the depth of 0$2.5 \mu \mathrm{m}(\mathrm{a})$ and (b) and $0-12 \mu \mathrm{m}(\mathrm{c})$ and (d) from the machined surface.

Fig. 10 (a)-(d) show the TEM images of the superficial layer at a depth of 0 to $8 \mu \mathrm{m}$ from the machined surface. It can be seen that the crystal defects are mainly formed by accumulation of 
dislocation tangles (DT), dislocation walls (DW) and mechanical twins (MT) in the white layer (Fig. 10a and b) while in the deformed bulk material layer (Fig. 10c and d) only DTs and DWs are found and no MTs appear. Moreover, in the recrystallisation layer (Fig. 10a, 0-2 $\mu \mathrm{m}$ from the machined surface) the density of intergranular defects is much lower than that in the transition and deformed bulk material layer, as most recrystallised grains have been fully developed and the dislocation defects around the grains have been absorbed. Interestingly, dislocations bowing out around the $\gamma^{\prime}$ precipitates are found in the deformed bulk material layer, while no distinct $\gamma^{\prime}$ precipitates could be found in the white layer. Coupled dislocations are also observed in the $\gamma-\gamma^{\prime}$ microstructure (Fig. 10d). The formation of subgrains is observed in the transition layer and the deformed bulk material, while pre-nuclei forming from pre-existing grain boundary toward the interior of a highly strained grain boundaries are also found (Fig. 10b and c). Due to the large strain induced by the mechanical load, the highly deformed crystalline structure generates high intragranular misorientation gradients, which constitute the prenuclei for recrystallisation. The nucleation starts with the pre-nuclei or subgrains and grows by absorbing its neighbouring pre-nuclei, subgrains and dislocations with thermally assisted low angle boundaries migration, thus increasing the orientation difference and generating the high angle grain boundary [37]. 


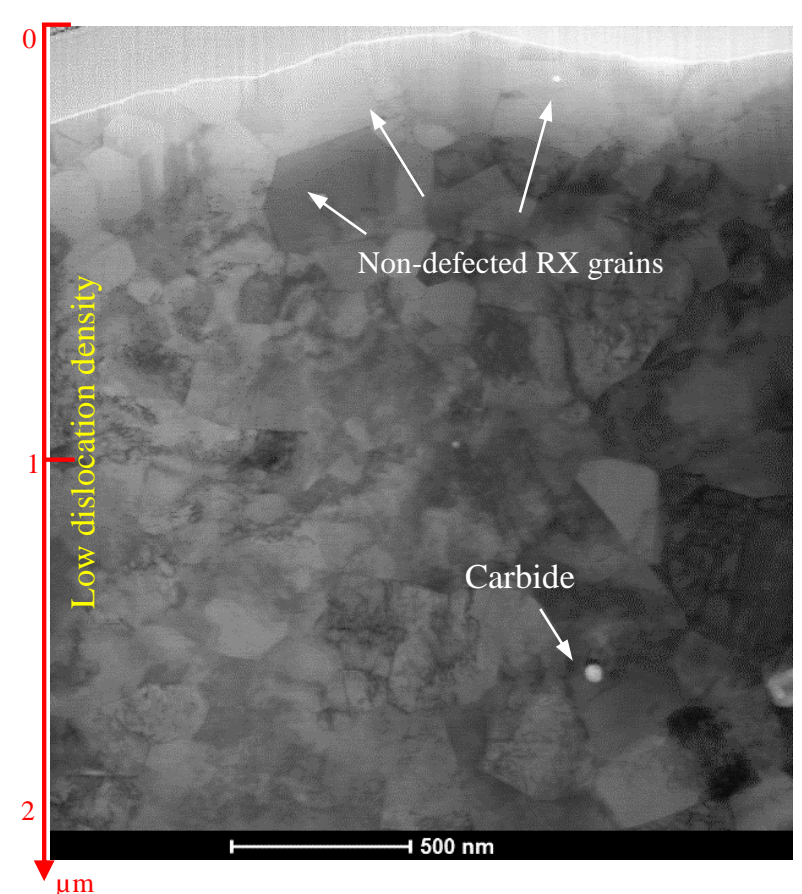

(a) Recrystallisation layer at depth of $0-2 \mu \mathrm{m}$ from surface

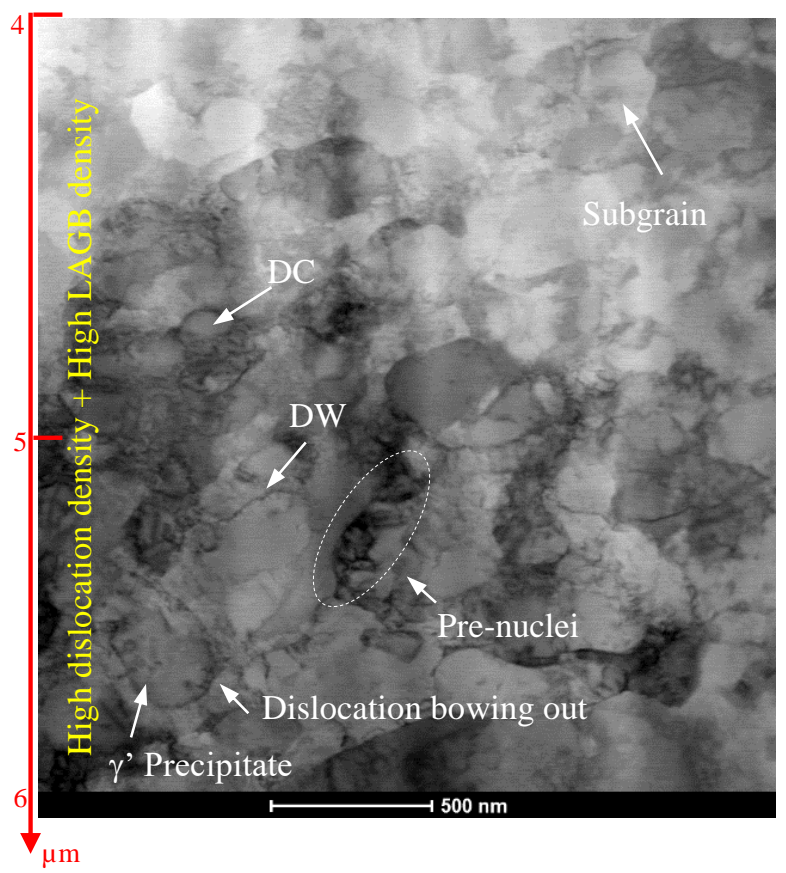

(c) Deformed bulk layer at depth of $4-6 \mu \mathrm{m}$ from surface

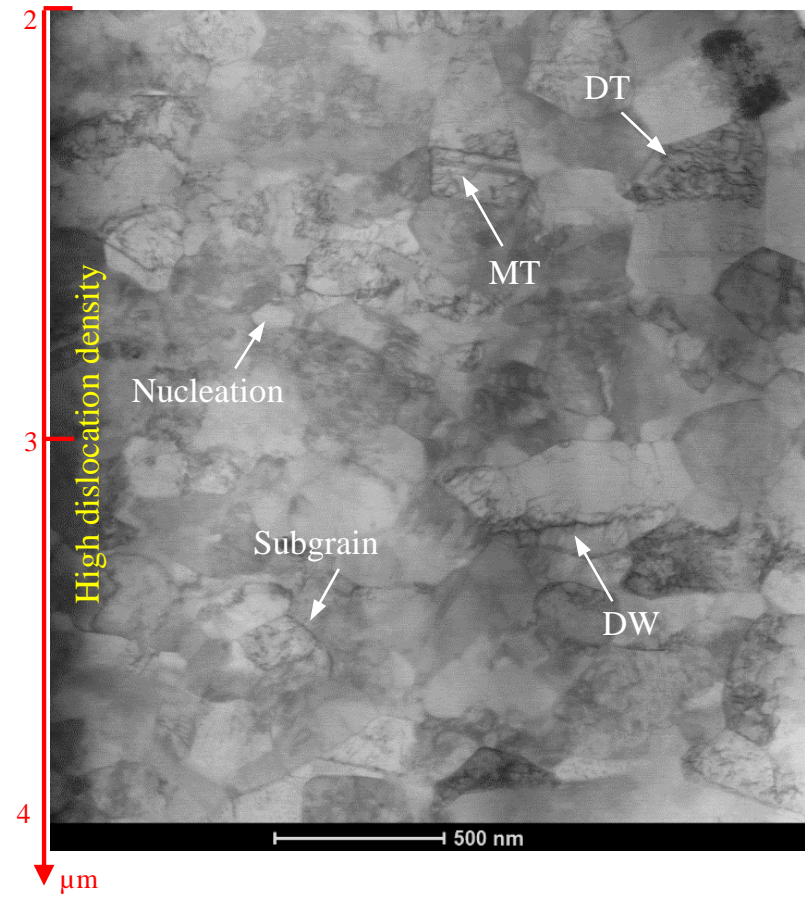

(b) Transition layer at depth of $2-4 \mu \mathrm{m}$ from surface

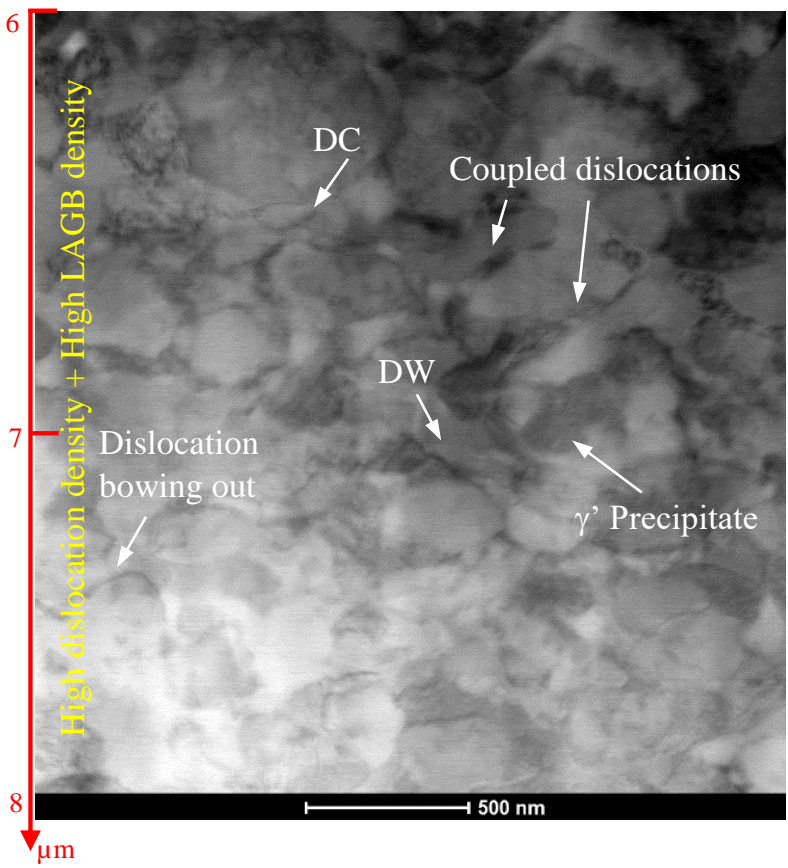

(d) Deformed bulk layer at depth of 6-8 $\mu \mathrm{m}$ from surface

Fig. 10 TEM micrographs of the superficial layer: (a)-(d) from free surface to the deformed bulk area.

Fig. 11 reveals the intragranular crystal defects in the white layer at the nanoscale, which are induced by the severe plastic deformation during the grain refinement process. Multifold nanotwinning is found in the refined grains (Fig. 11a), while dislocation cells are shown in transition layer 
(Fig 11b). The dislocation cells are developed from the intersections of the dislocation walls being transformed afterwards into subgrains or nuclei with annihilation and rearrangement of the dislocations for further development of the recrystallised grains.

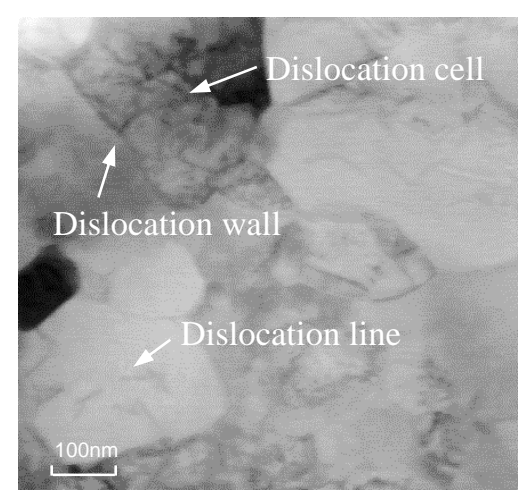

Fig. 11 Dislocation activities of the white layer at the nanoscale.

\subsection{Phase transition in the white layer}

To further understand the evolution of the chemical compositions in the affected layers, an elemental mapping of the $\gamma / \gamma^{\prime}$ elements containing the same areas analysed via TKD is shown in Fig. 12. A clear boundary between the white layer and deformed bulk material can be found in the elemental (e.g. Ni, Al, Cr) maps, findings which align well with the TKD crystallographic observations. More interestingly, a near uniform distribution of $\gamma / \gamma^{\prime}$ elements is also found at the top of the superficial layer $(0-2 \mu \mathrm{m})$, which corresponds to the recrystallisation layer and indicates the occurrence of $\gamma^{\prime}$ dissolution in this region. In the subsequent layer (transition layer) it can be observed that the $\gamma^{\prime}$ precipitates have been partially dissolved with a reduction in size, while being distorted under the effect of high temperature and high plastic strain induced by machining. 

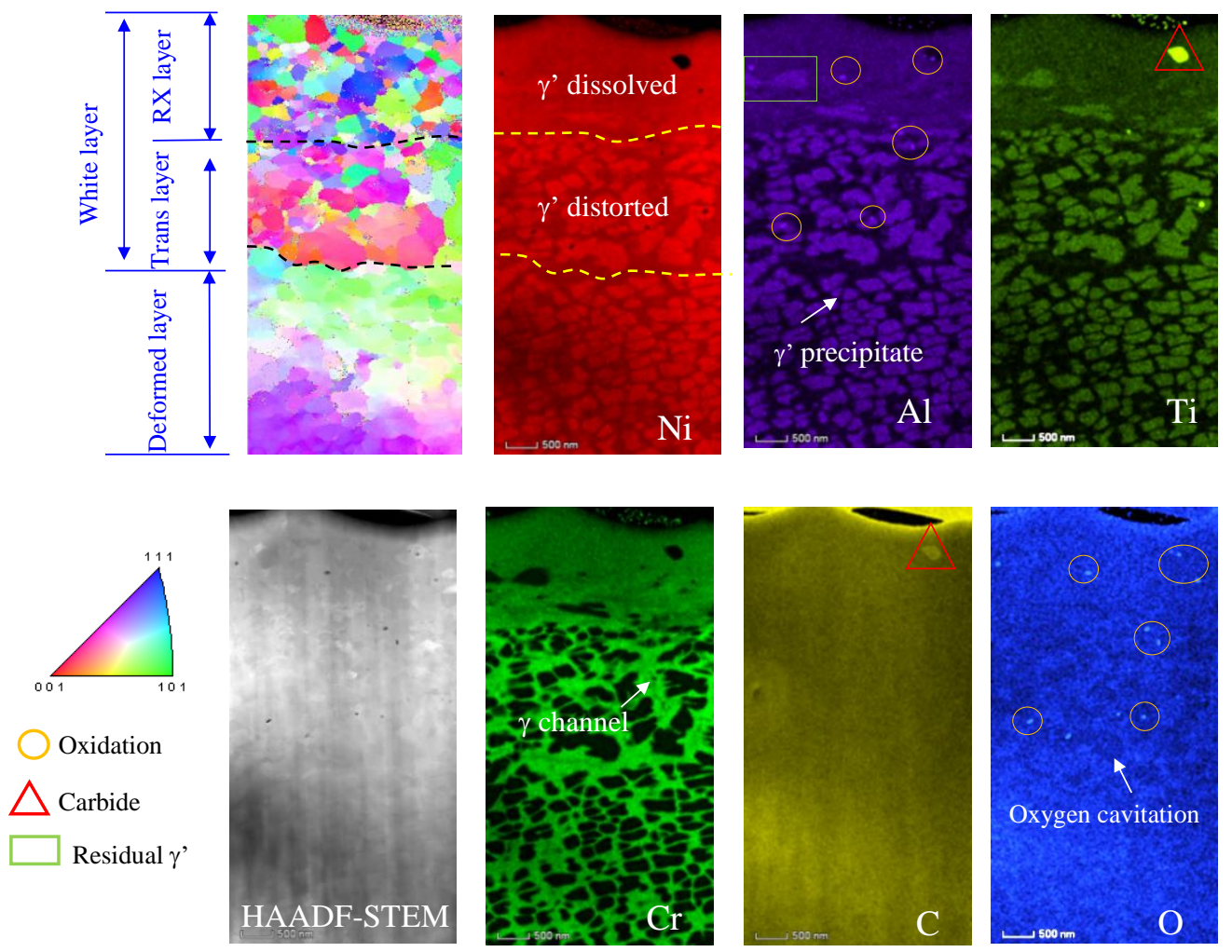

Fig. 12 Scanning TEM image and elemental distribution in superficial layer revealing the evolution of $\gamma^{\prime}$ in the machining process of a nickel-based superalloy

However, it also can also be seen that in the recrystallisation layer some primary $\gamma^{\prime}$ could not be fully dissolved due to the short temperature dwell time of the cutting edge engagement with the respective zone of the workpiece. This can be seen more clearly in Fig. 13 where some of the primary $\gamma^{\prime}$ particles are partially dissolved and consequently the morphology of these residual particles changes from cubic to a more irregular shape. No re-precipitation is found in this area, a conclusion which differs from other research $[6,31]$ which claimed that only grain refinement happens in the white layer of nickel-based superalloys, while no phase change occurs. 

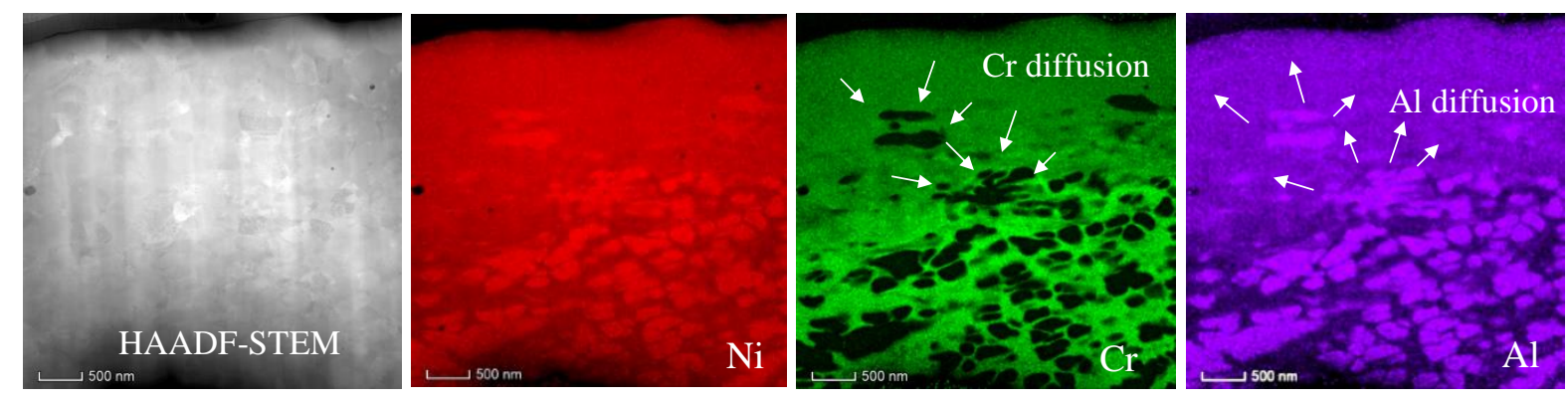

Fig. 13 EDX mapping of the elemental distribution showing the residual primary $\gamma^{\prime}$ particles in the recrystallization layer with the atom diffusion directions.

In the transition layer (Fig.12), the $\gamma^{\prime}$ precipitates are more distorted and partially dissolved, resulting in larger $\gamma$ channels in this layer than that in bulk layer. This grain distortion indicates that dislocation movement happened not only within the $\gamma$ phase but also inside the $\gamma^{\prime}$ precipitates. MC type carbide $(\mathrm{Ti} / \mathrm{Ta} / \mathrm{NbC})$ is also found in the recrystallisation layer, while oxidation is observed in both the recrystallisation layer and the transition layer (Fig. 12). The observed MC is from the original material, as this type of carbide is normally stable even at the temperature close to the melting point and it also present at other locations of the bulk material (Fig. 7a). Surprisingly, it also can be seen from the oxygen mapping that, in the transition layer, oxygen cavitation/pore appears in the site of the $\gamma^{\prime}$ precipitate, which means the $\gamma^{\prime}$ phase has a smaller oxide fraction than the $\gamma$ phase.

In the deformed bulk material layer, the $\gamma^{\prime}$ precipitates have not been dissolved but were partitioned with penetrating a certain dislocations. This can be also seen in Fig. 14, where the coupled dislocations penetrate through the $\gamma^{\prime}$ precipitates and cut the particles. Thus, based on the $\gamma^{\prime}$ phase evolution, the superficial layer can be divided into three layers: $\gamma^{\prime}$ dissolved layer, $\gamma^{\prime}$ distorted layer and $\gamma^{\prime}$ sheared layer, findings which support the observation of the phase evolution in the corresponding three crystallographic layers (recrystallisation, transition and deformed bulk material layer). This deterioration of the strengthening phase (i.e. $\gamma^{\prime}$ precipitates) may explain the significant plastic behaviour of the white layer observed previously in Fig. 7. 


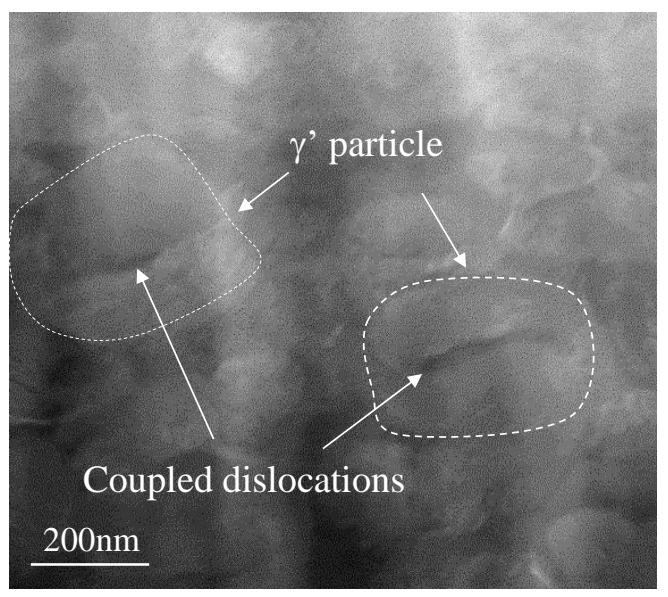

Fig. 14 Shear cut of $\gamma^{\prime}$ precipitate by coupled dislocation in the deformed bulk layer

\section{Discussion}

In the machining process the material above the cutting plane is removed by a moving wedgeshaped cutting tool with a shear deformation under high strain and strain rate. In the present study, the shear strain $\varepsilon$ in the cutting zone can be calculated as [38]:

$$
\varepsilon=\frac{\cos \alpha_{n}}{2 \sqrt{3} \sin \emptyset_{n} \cos \left(\emptyset_{n}-\alpha_{n}\right)}=\frac{1}{2 \sqrt{3} * \sin 40 \cos (40-0)}=1.3
$$

where the $\emptyset_{n,} \alpha_{n}$ are shear angle and tool rake angle, respectively. The shear angle can be calculated from Merchant theory in metal cutting mechanics [39].

The strain rate $\dot{\varepsilon}$ in the tool edge-workpiece interface can be estimated as [38]:

$$
\dot{\varepsilon}=\frac{2 V \cos \alpha_{n}}{\sqrt{3} h_{0} \cos \left(\emptyset_{n}-\alpha_{n}\right)}=\frac{2 * 80 * 10^{6} * 1}{\sqrt{3} * 0.5 * 100 * \cos (40-0) * 60}=40 * 10^{3} s^{-1}
$$

where $h_{0}$ is the primary shear zone thickness and can be estimated as half of the uncut chip thickness $(0.5 h), V$ is the cutting speed.

The equilibrium weight fractions for $\gamma, \gamma^{\prime}$ and liquid phase predicted by thermodynamic modelling (Thermo-Calc Software) for the $\mathrm{S} 135 \mathrm{H}$ are shown in Fig. 15 (a) over the temperature range of $500^{\circ} \mathrm{C}$ and $1500^{\circ} \mathrm{C}$. It can be seen that the predicted $\gamma^{\prime}$ solvus temperature of $\mathrm{S} 135 \mathrm{H}$ is approximately $1160^{\circ} \mathrm{C}$. 
More details of the alloy thermodynamics can be found in [34]. According to the thermal camera measurement of the machining process the cutting temperature in the tool edge-workpiece interface would reach around $1000{ }^{\circ} \mathrm{C}[4]$, while considering the measurement error (e.g. error of camera calibration for the alloy at high temperature and the shadow of tool in the cutting edge-workpiece interface) the real cutting temperature could reach values of around $1150-1200^{\circ} \mathrm{C}$, temperature at which $\gamma^{\prime}$ has a high percentage of solvation while the $\gamma$ reach higher percentage. This supports the previous observation that $\gamma^{\prime}$ is dissolved and partially dissolved in the recrystallisation and transition layers, respectively (Fig. 13). This, combined with the previous observation of dislocation activities, can describe the dissolution of $\gamma^{\prime}$ precipitates into two stages: at first, due to the high dislocation density, the dislocations could deform and penetrate through the $\gamma^{\prime}$ precipitates and divide them into small sizes, which leads to a thermodynamic instability of the $\gamma^{\prime}$ precipitates; secondly, the high temperature developed during cutting accelerates the diffusion of the thermodynamically instable $\gamma^{\prime}$ elements (i.e. $\mathrm{Al}, \mathrm{Ti}, \mathrm{Nb}$ and $\mathrm{Ta}$ ) into the $\gamma$ matrix which leads to the dissolution of $\gamma^{\prime}$ precipitates even at a temperature below the solvus point.

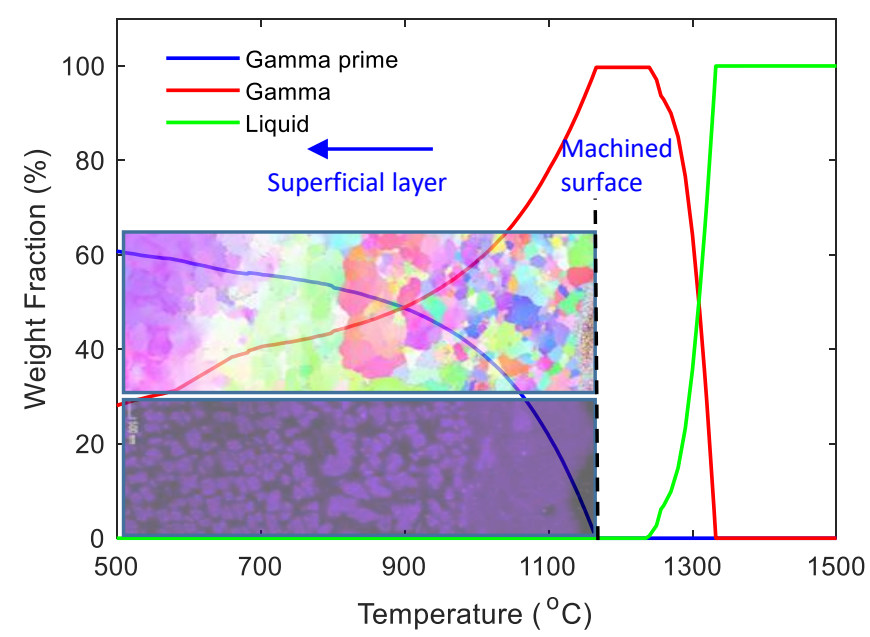

Fig. 15 Predicted equilibrium phase diagram of S135H. The Insert images are TKD and EDX mapping (Al) of the superficial layer representing the microstructural and chemistry evolution along the subsurface.

Using the experimental cutting temperature in corroboration with an analytical model of the temperature profile in a machined surface layer in orthogonal cutting $[4,40]$ the equivalent cooling 
rate on the workpiece surface could be approximated as around $10^{6}{ }^{\circ} \mathrm{C} / \mathrm{s}$. The estimated high cooling rate is much higher than the one found in conventional heat treatment process, due to the high speed of the moving heat source (i.e. cutting tool) and small thickness of the thermal affected layer [40, 41]. With this high cooling rate, the atomic diffusion would be frozen in the superficial layer, as there is no sufficient time to allow the precipitation of dissolved atoms. In particular, the $\gamma^{\prime}$ constitutive elements would not have enough time to reach the interface of the precipitates with the decreased diffusivity and this would result in a top surface layer ( $\gamma^{\prime}$ dissolved layer) consisting of a supersaturated $\gamma$ phase with $\gamma^{\prime}$ forming elements (e.g. $\mathrm{Al}, \mathrm{Ti}, \mathrm{Nb}$ and $\mathrm{Ta}$ ) or superfine $\gamma^{\prime}$ nuclei, which is similar to previous observations in other processes (e.g. friction welding and water quenching) [42, 43]. Hence, the growth of $\gamma^{\prime}$ particles in this layer is expected to be suppressed and the precipitate size minimized, as previously shown in Fig 13. On the other hand, this change of $\gamma^{\prime}$ phase also explains the lack of elasticity of the white layer and hence the softening behaviour of the nickel-based alloy when containing this thin layer.

Thus, based on the phase evolution analysis observed beneath the machined surface, the superficial layer can be identified in three different regions: (1) $\gamma^{\prime}$ dissolved layer where the secondary and tertiary $\gamma^{\prime}$ precipitates are fully dissolved while the primary $\gamma^{\prime}$ precipitates are partially dissolved due to the high temperature and high strain/strain rate; (2) $\gamma^{\prime}$ distorted layer where the $\gamma^{\prime}$ precipitates start to be dissolved due to the relative high temperature and are distorted with high dislocation density; and (3) $\gamma^{\prime}$ sheared layer where the accumulated dislocations either pile-up/bow around $\gamma^{\prime}$ precipitates or shear them by coupled dislocations, which results in plastic deformation of the $\gamma$ matrix with both elastic (dislocation bowing out) and plastic deformation (coupled dislocation) of $\gamma^{\prime}$ precipitates.

From the TKD and TEM observations it can be asserted that the white layer is not only formed by recrystallised grains, but it also includes a transition layer constituted by subgrains. It also can be observed that although the strain and strain rate induced by mechanical machining decreases along the 
depth of the workpiece, the dislocation density in the transition layer (Fig. 10b) is higher than that in the recrystallisation layer itself (Fig. 10a). This phenomenon is due to the dislocation rearrangement needed for forming the large angle grain boundaries and eventually the refined grains in the recrystallisation layer, which is known as dynamic recrystallisation. Moreover, in the transition layer a great amount of subgrains have been found (Fig. 5 and 10b), which are mainly formed from partition of the original grains through dislocation annihilation and rearrangement, known as dynamic recovery, before they can develop into recrystallised grains with higher temperature and strain. This observation is different from previous research of Inconel 718 [44], where the initial coarse grains were believed to be subdivided by the mechanical twinning. In the present study, the dislocation activities involve the development from dislocation lines inside the grains to dislocation tangles and dislocation walls, wherein their intersections form the dislocation cells and subgrains which subsequently become refined grains. Thus, recrystallisation grains in the white layer do not nucleate in the classical way but rather grow pre-existing dislocation cells and subgrains initiated from dynamic recovery. The grain refinement mechanism of white layer could be illustrated with three steps, as shown in Fig. 16:

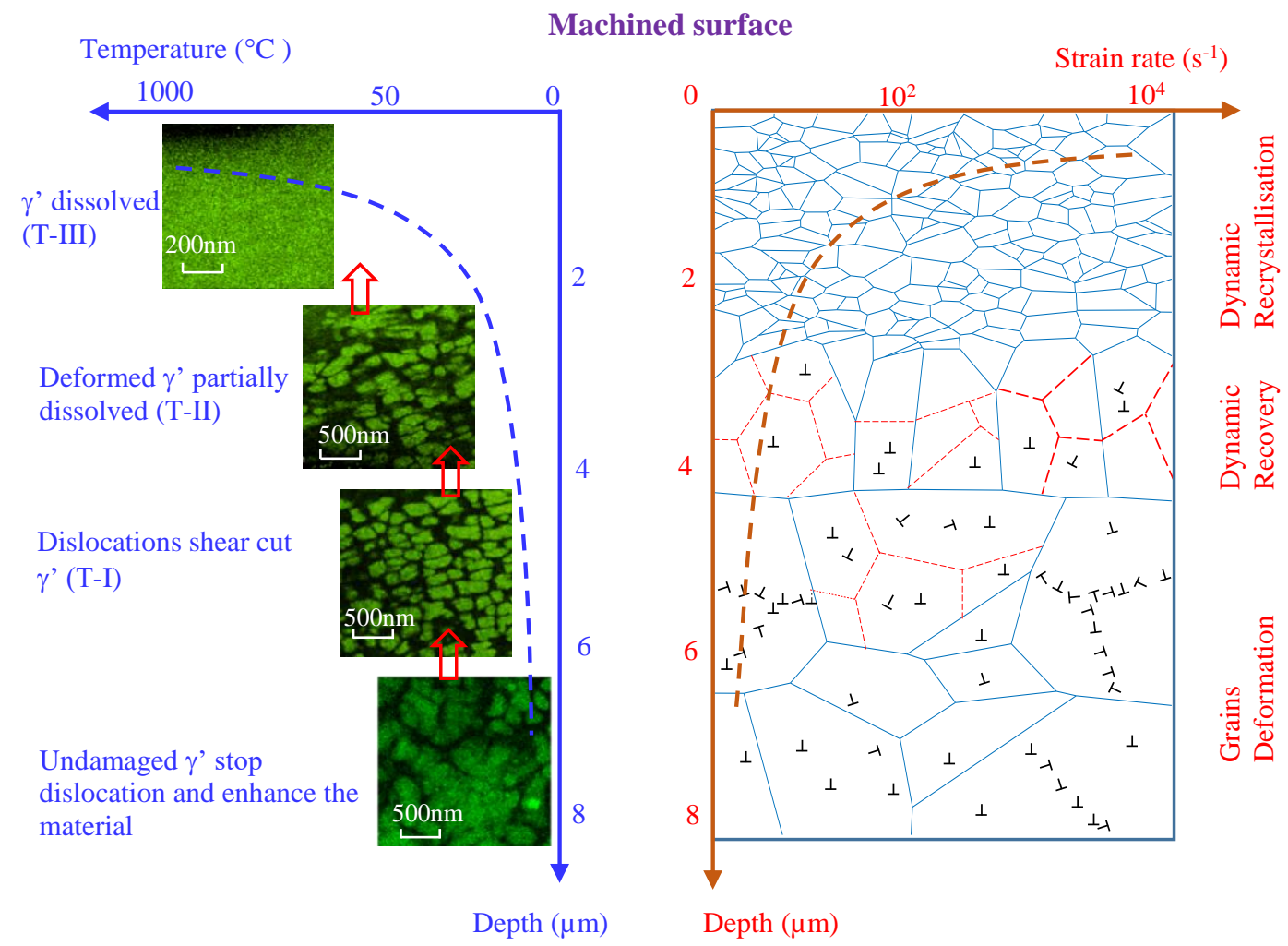


Fig. 16 Schematic illustration of grain refinement mechanism in white layer showing the phase and grain structure evolution with the high temperature and strain rate induced by machining.

Step I: The high strain and strain rate induced by machining process lead to the formation of high density dislocations, which develop into dislocation tangles and walls resulting in storage of the system energy in the form of crystalline defects (Fig. 9 and 10). The original coarse grains are then subdivided into dislocation cells by these dislocation tangles and walls (Fig. 10 and 11) and generate high local orientation gradients (Fig. 9). In this process, not only the $\gamma$ matrix has been plastically deformed by the high strain and strain rate, but the massive dislocations also bow around the $\gamma^{\prime}$ precipitates or shear (cut) them with coupled dislocations, generating both the elastic and plastic deformation of these $\gamma^{\prime}$ particles (Fig. 16-T-I). Thus, the dislocations accumulated in both the $\gamma$ channels and $\gamma^{\prime}$ precipitates and the coarse grains can be subdivided efficiently by the DTs and DWs.

Step II: With the further increase of strain rate and strain a higher dislocation density is generated. To decrease the stored energy, the dislocation cells will then absorb the accumulated dislocations and develop into subgrains or pre-nucleations which results in the transformation of the dislocation walls into low angle grain boundaries. In turn, these submicron subdivided blocks gradually become subgrain boundaries. In this stage, dynamic recovery dominates the grain evolution, while the insufficient energy leads to a disability to trigger the recrystallisation process. Moreover, the cutting temperature also increases, which combined with the high strain and strain rate, leads to partially dissolved and plastically deformed $\gamma^{\prime}$ precipitates and in turn reduces structural rigidities that hold down dislocation movement (Fig.16-T-II).

Step III: When cutting temperature reaches the highest value due to the direct engagement of the cutting tool and workpiecethe, the secondary and tertiary $\gamma^{\prime}$ precipitates are fully dissolved eventually, while the primary $\gamma^{\prime}$ precipitates are partially dissolved with the acceleration of atomic diffusion of $\gamma / \gamma^{\prime}$ constituent elements (Fig.16-T-III). At the same time, the formed subgrains absorb 
the dislocation faults around the grain and increase the grain boundary angles, thus generating nuclei. This process causes a large amount of dislocation annihilation and rearrangement of dislocation due to the high energy consumption for nucleation and growth of recrystallised grains. Eventually, the nuclei grow into entirely new strain-free grains with high angle grain boundaries. A high frequency of mechanical twins also occurs in this layer due to dissolution of $\gamma^{\prime}$ phase and high stress concentration. Due to the high cutting speed, the heat source (cutting tool) moves fast and results in a thin thickness of the thermally affected layer, while also leads to a ultra-high cooling rate. This high cooling rate results in the suppression of $\gamma^{\prime}$ precipitation and the growth of the recrystallised grains, as can be seen in Fig. 5 and 13. As a result, the microstructure is one of fine grain size containing a supersaturated $\gamma$ phase and $\gamma^{\prime}$ forming elements or superfine precipitates containing minimal intergranular defects.

\section{Conclusion}

The formation mechanism of the white layer in a next generation nickel-based superalloy induced by the high strain material removal process has been studied in detail. The crystallographic and chemical data of the nanocrystalline layer were captured with multi-resolution microscopic methods, and the micro-plasticity of this layer was investigated by in-situ loading-unloading cyclic compression testing of micro-pillars. For the first time a graded microstructure of the white layer induced by mechanical material removal in nickel-based superalloy has been revealed, while the $\gamma^{\prime}$ phase evolution has also been captured in the nanocrystalline structure. The main conclusions can be stated as follow:

1. A thin white layer induced by the severe plastic deformation during a machining process was generated in an advanced nickel-based superalloy, with a thickness of $\sim 3-4 \mu \mathrm{m}$. The white layer is composed of a dynamic recrystallisation layer of $\sim 200 \mathrm{~nm}$ sized grains and a dynamic recovery layer containing predominantly subgrains. Beneath the white layer there also exists a highly 
plastically deformed grain structure layer. A lower dislocation density was observed in the dynamic recrystallisation layer compared with both the dynamic recovery layer and the deformed bulk material layer, confirming the grain refinement process in the top surface layer. This leads to the first finding of this work, which explains the grain structure within the white layer of nickel-based superalloys under an aggressive machining condition.

2. The white layer showed a dominating micro-plasticity, but low elasticity in the loading-unloading cyclic compression test of micro-pillars, which for the first time reveals the elastoplastic behaviour of this thin layer. This is significantly different from the observation obtained in the bulk layer material and explains the softening behaviour of the aero-engine components displaying a superficial white layer.

3. An evolution of dislocation tangles and dislocation walls into dislocation cells, subgrains and subsequent refined grains was observed in the superficial layer under the different depths below the machined surface, explaining the occurrence of grain elongation, dynamic recovery and dynamic recrystallisation in the machining process of nickel-based superalloys. Meanwhile, the $\gamma$ ' precipitates in the superficial layer were subjected to shear cutting, distortion and dissolution activities when close to the machined surface. These evolutions of $\gamma^{\prime}$ assist the dislocation activities occurring inside the grains. The re-precipitation of dissolved $\gamma^{\prime}$ phase in the grain refinement layer is suppressed and minimized by the ultra-high cooling rate.

4. Based on the microstructural observations, a grain refinement mechanism induced by machining under high strain rates and temperatures was identified for this nickel-based superalloy, explaining the evolution of both the phases and grain structures. Experimental evidence and analysis of grain refinement mechanisms indicates the deterioration of the white layer with regard to the plasticity and mechanical strength in nickel-based superalloy. 


\section{Acknowledgement}

The authors would like to thank Rolls-Royce plc. for provision of material and financial support on this research. The authors are also grateful to Mr Steve Williams from Rolls-Royce plc., Derby, for his interpretation of the material behaviour from micro-mechanics testing.

\section{References}

[1] Huang, Guochao, G. Q. Liu, Minnan Feng, Ming Zhang, Benfu Hu, and Hao Wang. "The effect of cooling rates from temperatures above the $\gamma^{\prime}$ solvus on the microstructure of a new nickel-based powder metallurgy superalloy." Journal of Alloys and Compounds 747 (2018): 1062-1072.

[2] Bagot, P. A. J., O. B. W. Silk, J. O. Douglas, S. Pedrazzini, D. J. Crudden, T. L. Martin, M. C. Hardy, M. P. Moody, and R. C. Reed. "An Atom Probe Tomography study of site preference and partitioning in a nickel-based superalloy." Acta Materialia125 (2017): 156-165.

[3] Liao, Z., Gao, D., Lu, Y., \& Lv, Z. (2016). Multi-scale hybrid HMM for tool wear condition monitoring. The International Journal of Advanced Manufacturing Technology, 84(9-12), 2437-2448.

[4] Liao, Z., Axinte, D., Mieszala, M., M'Saoubi, R., Michler, J., \& Hardy, M. (2018). On the influence of gamma prime upon machining of advanced nickel based superalloy. CIRP Annals.

[5] Thakur, A., and S. Gangopadhyay. "State-of-the-art in surface integrity in machining of nickel-based super alloys." International Journal of Machine Tools and Manufacture 100 (2016): 25-54.

[6] V. Bushlya, J. Zhou, F. Lenrick, P. Avdovic, J. Ståhl, Characterization of white layer generated when turning aged Inconel 718, Procedia Eng. 19 (2011) 60 - 66.

[7] Chen Zhe, Magnus Hörnqvist Colliander, Gustav Sundell, Ru Lin Peng, Jinming Zhou, Sten Johansson, and Johan Moverare. "Nano-scale characterization of white layer in broached Inconel 718." Materials Science and Engineering: A 684 (2017): 373-384.

[8] Shang, Z., Liao, Z., Sarasua, J. A., Billingham, J., \& Axinte, D. (2019). On modelling of laser assisted machining: Forward and inverse problems for heat placement control. International Journal of Machine Tools and Manufacture, 138, 36-50.

[9] M'Saoubi, R., Larsson, T., Outeiro, J., Guo, Y., Suslov, S., Saldana, C., \& Chandrasekar, S. (2012). Surface integrity analysis of machined Inconel 718 over multiple length scales. CIRP AnnalsManufacturing Technology, 61(1), 99-102.

[10] Brown, Travis L., Christopher Saldana, Tejas G. Murthy, James B. Mann, Yang Guo, Larry F. Allard, Alexander H. King, W. Dale Compton, Kevin P. Trumble, and Srinivasan Chandrasekar. "A study of the interactive effects of strain, strain rate and temperature in severe plastic deformation of copper." Acta Materialia 57, no. 18 (2009): 5491-5500. 
[11] Shankar, M. Ravi, Balkrishna C. Rao, Seongeyl Lee, Srinivasan Chandrasekar, Alexander H.King, and W. Dale Compton. "Severe plastic deformation (SPD) of titanium at near-ambient temperature." Acta Materialia 54, no. 14 (2006): 3691-3700.

[12] Swaminathan, Srinivasan, M. Ravi Shankar, Seongyl Lee, Jihong Hwang, Alexander H. King, Renae F. Kezar, Balkrishna C. Rao et al. "Large strain deformation and ultra-fine grained materials by machining." Materials Science and Engineering: A 410 (2005): 358-363.

[13] Ding, Hongtao, and Yung C. Shin. "Dislocation density-based grain refinement modeling of orthogonal cutting of titanium." Journal of Manufacturing Science and Engineering 136, no. 4 (2014): 041003.

[14] Valiev, Ruslan. "Nanostructuring of metals by severe plastic deformation for advanced properties." Nature materials 3, no. 8 (2004): 511.

[15] Champion, Yannick, Cyril Langlois, Sandrine Guérin-Mailly, Patrick Langlois, Jean-Louis Bonnentien, and Martin J. Hÿtch. "Near-perfect elastoplasticity in pure nanocrystalline copper." Science 300, no. 5617 (2003): 310-311.

[16] Ye, Chang, Sergey Suslov, Xueling Fei, and Gary J. Cheng. "Bimodal nanocrystallization of NiTi shape memory alloy by laser shock peening and post-deformation annealing." Acta materialia 59, no. 19 (2011): 7219-7227.

[17] Lu, J. Z., K. Y. Luo, Y. K. Zhang, C. Y. Cui, G. F. Sun, J. Z. Zhou, L. Zhang, J. You, K. M. Chen, and J. W. Zhong. "Grain refinement of LY2 aluminum alloy induced by ultra-high plastic strain during multiple laser shock processing impacts." Acta Materialia 58, no. 11 (2010): 3984-3994.

[18] Lu, J. Z., K. Y. Luo, Y. K. Zhang, G. F. Sun, Y. Y. Gu, J. Z. Zhou, X. D. Ren et al. "Grain refinement mechanism of multiple laser shock processing impacts on ANSI 304 stainless steel." Acta Materialia 58, no. 16 (2010): 5354-5362.

[19] P.P. Bhattacharjee, R.K. Ray, N. Tsuji, Cold rolling and recrystallization textures of a Ni-5 at.\%Walloy, Acta Mater. 57 (2009) 2166-2179.

[20] Shin, D. H., I. Kim, J. Kim, Y. S. Kim, and S. L. Semiatin. "Microstructure development during equalchannel angular pressing of titanium." Acta Materialia 51, no. 4 (2003): 983-996.

[21] Xu, Cheng, Steven Schroeder, Patrick B. Berbon, and Terence G. Langdon. "Principles of ECAPConform as a continuous process for achieving grain refinement: Application to an aluminum alloy." Acta Materialia 58, no. 4 (2010): 1379-1386.

[22] A. Zafari, X.S. Wei, W. Xu, K. Xia, Formation of nanocrystalline b structure in metastable beta Ti alloy during high pressure torsion: the role played by stress induced martensitic transformation, Acta Mater. 97 (2015) 146e155.

[23] Müller, T., M. W. Kapp, A. Bachmaier, P. Felfer, and R. Pippan. "Ultrahigh-strength low carbon steel obtained from the martensitic state via high pressure torsion." Acta Materialia(2018).

[24] Deng, W. J., Xia, W., Li, C., and Tang, Y., 2010, “Ultrafine Grained Material Produced by Machining," Mater. Manuf. Process., 25(6), pp. 355-359. 
[25] Ding, Hongtao, Ninggang Shen, and Yung C. Shin. "Modeling of grain refinement in aluminum and copper subjected to cutting." Computational Materials Science 50, no. 10 (2011): 3016-3025.

[26] Shankar, M. Ravi, Balkrishna C. Rao, Seongeyl Lee, Srinivasan Chandrasekar, Alexander H. King, and W. Dale Compton. "Severe plastic deformation (SPD) of titanium at near-ambient temperature." Acta Materialia 54, no. 14 (2006): 3691-3700.

[27] Ding, Hongtao, and Yung C. Shin. "Dislocation density-based grain refinement modeling of orthogonal cutting of titanium." Journal of Manufacturing Science and Engineering 136, no. 4 (2014): 041003.

[28] M'Saoubi, Rachid, Dragos Axinte, Christopher Herbert, Mark Hardy, and Paul Salmon. "Surface integrity of nickel-based alloys subjected to severe plastic deformation by abusive drilling." CIRP AnnalsManufacturing Technology 63, no. 1 (2014): 61-64.

[29] Herbert, C., D. A. Axinte, M. Hardy, and P. Withers. "Influence of surface anomalies following hole making operations on the fatigue performance for a nickel-based superalloy." Journal of Manufacturing Science and Engineering 136, no. 5 (2014): 051016.

[30] D. Ulutan, T. Ozel, Machining induced surface integrity in titanium and nickel alloys: a review, Int. J. Mach. Tools Manuf. 51 (2011) 250 - 280.

[31] Herbert, C. R. J., D. A. Axinte, M. C. Hardy, and P. D. Brown. "Investigation into the characteristics of white layers produced in a nickel-based superalloy from drilling operations." Procedia Engineering 19 (2011): 138-143.

[32] Hosseini, S. B., U. Klement, Y. Yao, and K. Ryttberg. "Formation mechanisms of white layers induced by hard turning of AISI 52100 steel." Acta Materialia 89 (2015): 258-267.

[33] Hosseini, S. B., Mattias Thuvander, Uta Klement, Gustav Sundell, and Kristina Ryttberg. "Atomic-scale investigation of carbon atom migration in surface induced white layers in high-carbon medium chromium (AISI 52100) bearing steel." Acta Materialia 130 (2017): 155-163.

[34] M.C Hardy, H.J. Stone, P.M. Mignanelli, B.D. Conduit and G.J. Conduit. A nickel alloy, European Patent, EP2805784B1, 3 June 2015.

[35] Tumbajoy-Spinel, David, Xavier Maeder, Gaylord Guillonneau, Sergio Sao-Joao, Sylvie Descartes, JeanMichel Bergheau, Cécile Langlade, Johann Michler, and Guillaume Kermouche. "Microstructural and micromechanical investigations of surface strengthening mechanisms induced by repeated impacts on pure iron." Materials \& Design 147 (2018): 56-64.

[36] Fan, G. D., M. Y. Zheng, X. S. Hu, K. Wu, W. M. Gan, and H. G. Brokmeier. "Internal friction and microplastic deformation behavior of pure magnesium processed by equal channel angular pressing." Materials Science and Engineering: A 561 (2013): 100-108.

[37] Rios, Paulo Rangel, Fulvio Siciliano Jr, Hugo Ricardo Zschommler Sandim, Ronald Lesley Plaut, and Angelo Fernando Padilha. "Nucleation and growth during recrystallization." Materials Research 8, no. 3 (2005): 225-238.

[38] P.L.B. Oxley, The Mechanics of Machining: An Analytical Approach to Asses- sing Machinability, Ellis Horwood Limited, England, 1989. 
[39] M.E. Merchant, Mechanics of the metal cutting process, II. Plasticity conditions in orthogonal cutting, J.Appl.Phys.16 (1945) 318-324.

[40] Huang, Kun, and Wenyu Yang. "Analytical model of temperature field in workpiece machined surface layer in orthogonal cutting." Journal of Materials Processing Technology 229 (2016): 375-389.

[41] Grant, Benedict MB, Elisabeth M. Francis, Joao Quinta da Fonseca, Mark R. Daymond, and Michael Preuss. "Deformation behaviour of an advanced nickel-based superalloy studied by neutron diffraction and electron microscopy." Acta Materialia 60, no. 19 (2012): 6829-6841.

[42] Chamanfar, A., M. Jahazi, J. Gholipour, P. Wanjara, and S. Yue. "Mechanical property and microstructure of linear friction welded Waspaloy." Metallurgical and Materials Transactions A 42, no. 3 (2011): 729-744.

[43] Babu, S. S., M. K. Miller, J. M. Vitek, and S. A. David. "Characterization of the microstructure evolution in a nickel base superalloy during continuous cooling conditions." Acta Materialia 49, no. 20 (2001): 4149-4160.

[44] Ren, X. P., Liu, Z. Q. "Microstructure refinement and work hardening in a machined surface layer induced by turning Inconel 718 super alloy." International Journal of Minerals, Metallurgy, and Materials, 25 no. 8 (2018): 937-949. 